\title{
Post-esophageal banding ulcers and proton-pump inhibitors: Friend or foe?
}

\author{
Graziella Rangel-Paniz ${ }^{1}$ and Sergio A. Sánchez-Luna ${ }^{2 *}$ \\ ${ }^{1}$ Department of Internal Medicine, The University of New Mexico School of Medicine, Albuquerque, New Mexico; ${ }^{2}$ Center for Advanced Therapeutic \\ Endoscopy, Division of Gastroenterology, Hepatology and Nutrition, Allegheny Health Network/Allegheny Center for Digestive Health, Pittsburgh. \\ United States of America
}

\begin{abstract}
Gastroesophageal varices are a common complication from portal hypertension. Endoscopic variceal banding is currently recommended by guidelines as both therapeutic, in case of hemorrhage, and prophylactic measure. In this brief case report, we try to highlight the importance of proton-pump inhibitors to prevent post-banding ulcer bleeding.
\end{abstract}

Key words: Gastroesophageal varices. Esophageal banding. Proton-pump inhibitor. Post-banding ulcer bleeding.

\section{Úlceras de bandas esofágicas posteriores a ligadura endoscópica e inhibidores de la bomba de protones: ¿amigo o enemigo?}

\section{Resumen}

Las várices gastroesofágicas (VGEs) son una complicación común de la hipertensión portal. La aplicación de bandas en várices por ligadura endoscópica se recomienda actualmente en las guías terapéuticas, en caso de hemorragia, y como medida profiláctica. En este breve informe de caso, tratamos de resaltar la importancia de los inhibidores de la bomba de protones (IBPS) para prevenir el sangrado de úlcera post-ligadura.

Palabras claves: Várices gastroesofágicas. Ligadura de Varices. Inhibidores de la Bomba de Protones. Sangrado de Úlcera Post-ligadura Endoscópica.

\section{Introduction}

Gastroesophageal varices (GEVs) are a common complication from portal hypertension. Endoscopic variceal banding is currently recommended by guidelines as both therapeutic, in case of hemorrhage, and prophylactic measure. In this brief case report, we highlight the importance of proton-pump inhibitors (PPIs) to prevent post-banding ulcer bleeding (PBUB).

\section{Case report}

A 70-year-old male with a new diagnosis of decompensated alcoholic cirrhosis was referred for esophagogastroduodenoscopy for esophageal variceal screening. Three columns of medium-sized varices were banded $\times 4(1 \mathrm{~A})$ and he continued on twice a day pantoprazole previously prescribed for chronic heartburn. One week after, he developed one episode of
Date of reception: 08-05-2020

Date of acceptance: 13-07-2020 DOI: 10.24875/END.20000038
Available online: 06-11-2020

Endoscopia. 2020;32(4):140-142

www.endoscopia-ameg.com artículo open access bajo la licencia CC BY-NC-ND (http://creativecommons.org/licenses/by-nc-nd/4.0/). 
hematemesis. The patient was not on any anticoagulants. On admission, blood pressure was $95 / 54 \mathrm{mmHg}$ and heart rate was 104 beats/min. Physical examination revealed prominent collaterals vessels and moderate ascites. Hemoglobin was $8.2 \mathrm{~g} / \mathrm{dL}$ and platelet count was $169,000 \mathrm{~K} / \mathrm{mm}^{3}$. INR was 1.4 and albumin was $2.9 \mathrm{~g} / \mathrm{dL}$. His model for end-stage liver disease (MELD)Na was 14. He underwent volume resuscitation and was given pantoprazole, octreotide, and ceftriaxone. Urgent endoscopy showed 3 , non-bleeding, post-variceal banding ulcers (1B) with one having an underlying healing varix (1C). No additional endoscopic interventions were performed. He continued a PPI and he was also started on liquid sucralfate. His condition stabilized with no further bleeding and he was discharged 2 days later.

\section{Discussion}

GEVs are present in approximately half of patients with cirrhosis, depending on the clinical stage. In patients with compensated cirrhosis, GEVs are present in $30-40 \%$, whereas they can be present in up to $85 \%$ of patients with decompensated disease. Endoscopic variceal ligation (EVL) (banding) is a local therapy that consists of placing rubber bands around esophageal varices in repeated sessions until they become obliterated and it is currently recommended by guidelines as both therapeutic, in case of hemorrhage, and prophylactic measure. However, because it is a local therapy that has no effect on portal hypertension $(\mathrm{PH})$, recurrence of varices is the rule, and the patients require indefinite endoscopic monitoring.

Approximately 3 days -1 week after the application of the rubber bands, the ligated varix sloughs off leaving a shallow ulcer that typically heals in 2-3 weeks ${ }^{2}$. However, in some rare cases, these ulcers can bleed - the reported incidence of PBUB varies from $2.6 \%$ to $7.3 \%{ }^{3}$. Associated risk factors with PBUB include Child-Pugh Class $C$ status, acute variceal hemorrhage, high platelet ratio index, and low prothrombin index ${ }^{3}$.

A few studies have pointed out that gastric acid secretion has an important role in delaying post-banding ulcers from healing, so a course of PPI after endoscopic variceal banding could be indicated for PBUB prophylaxis. Lo et al. performed a systematic review outlining that a short course of 10 days of PPIs may be reasonable if ulcer healing is a concern although high-dose $\mathrm{PPI}$ and/or prolonged use in the absence of endoscopic procedure should be discouraged ${ }^{4}$. Shaheen et al. found $50 \%$ reduction in the size of post-banding ulcers at follow-up endoscopies 10-14 days after initial banding

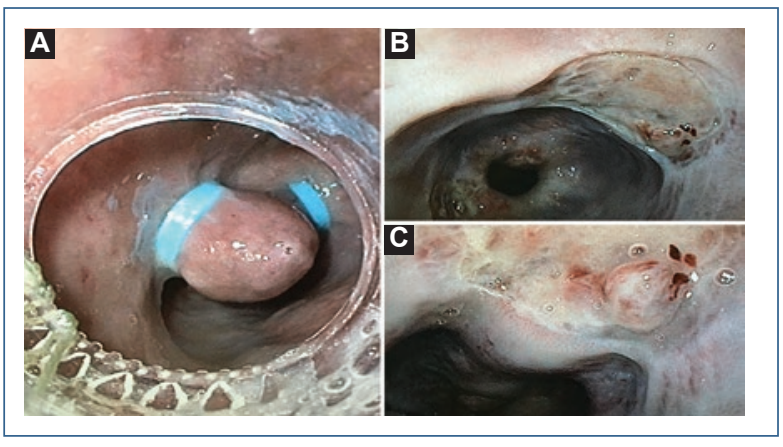

Figure 1. A: Medium-sized esophageal varices status post endoscopic rubber band ligation. B: Non-bleeding postesophageal banding ulcers. C: Post-banding esophageal ulcer with a prominent underlying, non-bleeding, healing varix.

with $40 \mathrm{mg}$ of pantoprazole daily, however, decrease in bleeding episodes and morbidity were not assessed in this study ${ }^{2}$. Kang et al. aimed to analyze the factors associated with bleeding after prophylactic EVL and to assess the effect of PPI therapy. A total of 505 patients were included in this retrospective cohort study that demonstrated that not initiating PPI therapy was the only positive predictive factor for a bleeding complication in patients who received EVL without gastric varix therapy ${ }^{5}$.

Sucralfate has also been shown by Sakr et al. to be effective in decreasing the rate of occurrence $(74 \%$ vs. $38 \%, p=0.005$ ) and the size of post-esophageal variceal banding ulcers ${ }^{6}$.

At present, there is no standard guideline measure for PBUB prevention and the role of PPI for hemorrhage prophylaxis remains not entirely clear. However, we do believe that given its low cost and wide availability, PPIs could be an excellent tool for prevention in post-esophageal banding ulcer bleeding. Further investigation will be required to delineate the targeted population for this approach.

\section{Specific authors' contributions}

GR Paniz and SA Sánchez-Luna collected data and wrote the manuscript and revised the manuscript for intellectual content. SA Sánchez-Luna is the article guarantor. SA Sánchez-Luna revised the manuscript for intellectual content and the endoscopy imaging. All authors involved in this report approved the final version.

\section{Conflicts of interest}

None to report. 


\section{Funding}

None to report.

\section{Ethical disclosures}

Protection of human and animal subjects. The authors declare that no experiments were performed on humans or animals for this study.

Confidentiality of data. The authors declare that they have followed the protocols of their work center on the publication of patient data.

Right to privacy and informed consent. The authors have obtained the written informed consent of the patients or subjects mentioned in the article. The corresponding author is in possession of this document.

\section{References}

1. Garcia-Tsao G, Abraldes JG, Berzigotti A, Bosch J. Portal hypertensive bleeding in cirrhosis: risk stratification, diagnosis, and management: 2016 practice guidance by the American association for the study of liver diseases. Hepatology. 2017:65:310-35.

2. Shaheen NJ, Stuart E, Schmitz SM, Mitchell KL, Fried MW, Zacks S, et al. Pantoprazole reduces the size of postbanding ulcers after variceal band ligation: a randomized, controlled trial. Hepatology. 2005; 41:588-94.

3. Tierney A, Toriz BE, Mian S, Brown KE. Interventions and outcomes of treatment of postbanding ulcer hemorrhage after endoscopic band ligation: a single-center case series. Gastrointest Endosc. 2013; 77:136-40.

4. Lo EA, Wilby KJ, Ensom MH. Use of proton pump inhibitors in the management of gastroesophageal varices: a systematic review. Ann Pharmacother. 2015;49:207-19.

5. Kang SH, Yim HJ, Kim SY, Suh SJ, Hyun JJ, Jung SW, et al. Proton pump inhibitor therapy is associated with reduction of early bleeding risk after prophylactic endoscopic variceal band ligation: a retrospective cohort study. Medicine (Baltimore). 2016;95:e2903.

6. Sakr MA, Hamed WA, Gafaary MM, El-Folly RF, El-Hamamsy M. Role of sucralfate in promoting healing of post band variceal ulcer. Adv Natl Sci. 2011;4:7-14. 